\title{
A BASE DE CÁlCULO DO ICMS SOBRE AS BONIFICAÇÕES EM MERCADORIA NO ESTADO DE SÃO PAULO
}

\author{
Leonardo Anacleto Chaves ${ }^{1}$
}

RESUMO: O Fisco Estadual exige o recolhimento de ICMS sobre as operações bonificadas, exigência esta inconstitucional. A natureza da bonificação é o abatimento dado sob a forma física da mercadoria. Relativamente à própria operação de saída do estabelecimento comercial, sendo incondicional, deve ser excluído da base de cálculo do ICMS o valor das mercadorias bonificadas, nos termos da Constituição Federal e Código Tributário Nacional, ao disporem que a base de cálculo do imposto corresponde ao valor da operação. No entanto, a Fazenda do Estado de São Paulo, inconstitucionalmente, passou a exigir o ICMS sobre as mercadorias bonificadas a partir da Decisão Normativa CAT 4, de $30 / \mathrm{II} / 2000$.

Palavras-chave: ICMS. Base de cálculo. Bonificação em Mercadoria.

ABSTRACT: The State Treasury department demands the ICMS collect on the free goods operations, requirement this unconstitutional one. The nature of the free goods is the reduction given under the physical form of the merchandise. Relatively to the proper operation of exit of the commercial establishment, being unconditional, the value of the granted money merchandise must be excluded from the taxable income of the ICMS, in the terms of the Federal Constitution and National Tributary Code, when making use that the tax base of the tax corresponds to the value of the operation. However, the State Treasury department of the State of São Paulo, in a unconstitutional act, started to demand the ICMS on the free goods from the Normative Decision CAT 4, of 30/II/200o.

Keywords: ICMS. Tax Base. Free Goods.

\section{INTRODUÇÃO}

No desenvolvimento das relações comerciais é comum a prática da concessão de descontos ou de bonificações em mercadorias. Essa forma de comercialização visa, como é notório, o aumento das vendas e dos lucros das empresas, mas pode representar, também, uma forma de manutenção de uma fatia de mercado, abalado por crescente aumento da

I Advogado Bacharel em Direito - Faculdade de Direito de Bauru - ITE Instituição Toledo de Ensino Pós Graduação Especialização em Direito Tributário - IBPEX - UNINTER MBA Varejo e Mercado de Consumo - USP ESALQ 
competitividade entre os agentes econômicos. Trata-se de estratégia de venda que traduz uma vantagem que o vendedor concede ao comprador que preenche certos requisitos como a compra de quantidades mínimas etc ${ }^{2}$.

A legislação vigente estabelece, como restará demonstrado a seguir, que o tributo ICMS incide sobre as operações relativas à circulação de mercadorias, excluindo-se de sua base de cálculo os descontos incondicionais, como é o caso das bonificações, sendo especificamente prevista tal exclusão no artigo I3, parágrafo Io, inciso II, alínea "a", da Lei Complementar n. ${ }^{\circ} 87$, de 13 de setembro de 1996, bem como no artigo 24, parágrafo Io, da Lei n. ${ }^{\circ}$ 6.374/89, com a redação conferida pela Lei n. $\stackrel{0}{10.619 / o o . ~}$

No entanto, desde 09.12.200o, em total afronta à Constituição Federal e às leis em vigor, a Fazenda do Estado de São Paulo, através de seus Agentes Fiscais, tem adotado o posicionamento de que as bonificações integram a base de cálculo do ICMS, com base em decisão proferida pelo Coordenador da Administração Tributária, qual seja, a Decisão Normativa CAT n. ${ }^{4}$, de 30 de novembro de 20oo, publicada no Diário Oficial do Estado de 09.12.2000.

Todavia, tal situação é inconstitucional e ilegal, pois ofende o artigo Io combinado com o artigo 170, artigo 5을 inciso II, artigo 146, inciso III, alínea "a", artigo I50, inciso I, e artigo 155, inciso II, todos da Constituição Federal, artigos 6으 e $7^{\circ}$, ambos do Código Tributário Nacional, bem como afronta as leis específicas que prevêem a exclusão dos valores das bonificações da base de cálculo do tributo ICMS.

\section{O ICMS NÃO DEVE INCIDIR SOBRE O VALOR DAS MERCADORIAS REMETIDAS A TÍTULO DE BONIFICAÇÃO}

O artigo 155, inciso II, da Constituição Federal assim prescreve:

\footnotetext{
“Art. 155 - Compete aos Estados e ao Distrito Federal instituir impostos sobre:

II - operações relativas à circulação de mercadorias e sobre prestações de serviços de transporte interestadual e intermunicipal e de comunicação, ainda que as operações e as prestações se iniciem no exterior;"
}

Da leitura do artigo supratranscrito, é inquestionável que o fato gerador do ICMS refere-se à operação relativa à circulação de mercadorias. 
Ressalvada tal premissa e analisando-se especificamente as bonificações concedidas nos atos de comércio, tem-se que estas são, na verdade, um modo de o vendedor conseguir um melhor resultado em seus negócios, pois se caracterizam como uma quantidade maior que a efetivamente comprada sem que o vendedor cobre qualquer valor adicional pela diferença, caracterizando-se, portanto, como abatimento por meio de produtos.

Sendo assim, as bonificações caracterizam-se como incondicionais, pois, ainda que constantes nas notas fiscais de venda das mercadorias, não há qualquer contraprestação do comprador, e por esta razão, não integrante da operação mercantil e do fato gerador do tributo.

Diante do exposto, já podemos ir adiantando que o ICMS estará irremediavelmente descaracterizado se sua base de cálculo levar em conta elementos estranhos à operação mercantil realizada, como, por exemplo, o valor intrínseco dos bens entregues à título de bonificação, ou seja, sem a efetiva cobrança de um preço sobre eles.

De fato, não é o elemento constitutivo da base de cálculo do ICMS o valor que poderia ser obtido caso as mercadorias bonificadas tivessem sido postas in commercium.

É que bonificação, em última análise, é um mero estímulo à compra. Nesta medida, corresponde, em tudo e por tudo, a um desconto incondicional, que, por evidente, não integra a base de cálculo do ICMS, conforme aliás, expressamente reconhecido pela legislação de regência (interpretação a contrario sensu do artigo I3, § Iㅇ, II, $a$, da Lei Complementar 87/96)”,

Ademais, consoante mencionado no texto transcrito, a própria Lei Complementar n. $-87 / 96$, ao tratar da questão das bonificações, expressamente determina que os descontos incondicionais não integram a base de cálculo do tributo ICMS, pois prevê que somente integram a esta o montante recebido a título de seguros, juros e demais importâncias recebidas ou debitadas, bem como descontos concedidos sob condição:

Dispõe sobre o Imposto dos Estados e do Distrito Federal sobre operações relativas à circulação de mercadorias e sobre prestações de serviços de transporte interestadual e intermunicipal e de comunicação, e dá outras providências.

Art. 13-omissis

§ Iㅇ Integra a base de cálculo do imposto, inclusive na hipótese do inciso $\mathrm{V}$ do caput deste artigo: (Redação dada pela Lcp II4, de i6.12.2002)

II - o valor correspondente a:

a) seguros, juros e demais importâncias pagas, recebidas ou debitadas, bem como descontos concedidos sob condição;"

3 Carrazza, Roque Antonio. ICMS. 9.ed. São Paulo : Malheiros Editores, 2003, p. 106. 
Diante disso, resta claro que os descontos concedidos incondicionalmente não podem ser incluídos na base de cálculo do ICMS, posto que não previstos em Lei e não integrantes da operação mercantil, haja vista serem concedidos sem qualquer contraprestação do beneficiário do desconto.

Ressalte-se, ainda, que o Estado de São Paulo, em legislação específica, tem em sua norma dispositivo vigente semelhante ao artigo supratranscrito, qual seja, o artigo 24, § Iㅇ, da Lei n.ำ 6.374/89, com redação conferida pela Lei n.ำ ı.6ı/oo. Vejamos:

Artigo 24 - Ressalvados os casos expressamente previstos, a base de cálculo do imposto nas hipóteses do artigo º é: (Redação dada pelo inciso XIII do art. Io da Lei 10.619, de 19.7.00, DOE 20.7.00)

§ I으- Incluem-se na base de cálculo:

I - seguros, juros e demais importâncias pagas, recebidas ou debitadas, bem como descontos concedidos sob condição;"

No entanto, na contramão ao disposto, tanto na Constituição Federal quanto na legislação específica, a Fazenda do Estado de São Paulo, através de seus Agentes Fiscais, ignora tais previsões, aplicando única e exclusivamente o disposto em uma decisão proferida pelo Coordenador da Administração Tributária, a Decisão Normativa CAT 4, de 30 de novembro de 200o, publicada no Diário Oficial do Estado de 09.12.20oo, que assim dispõe:

Decisão Normativa CAT 4, de 30.11.2000 (DOE de 09.12.2000) - ICMS Bonificações - Dispõe sobre a inclusão do valor das mercadorias bonificadas na base de cálculo do imposto.

O Coordenador da Administração Tributária, tendo em vista o disposto no artigo 587 do Regulamento do ICMS, aprovado pelo Decreto n. ${ }^{\circ}$ 33.118, de 14/3/91, decide:

I - fica aprovada a resposta dada pela Consultoria Tributária à Consulta n.o $559 / 2000$, cujo texto é reproduzido em anexo a esta decisão, no sentido de que segundo o disposto no artigo 24 , § I ${ }^{\circ}$, item I, da Lei n.o 6.374/89 (Redação dada pela Lei n.o 10.619 , de 19.07.2000) devem fazer parte da base de cálculo do imposto os " seguros, juros e demais importâncias pagas, recebidas ou debitadas, bem como descontos concedidos sob condição”, aí incluídas as bonificações, entendidas como abatimento na forma de mercadorias, por não se confundirem com desconto, este entendimento como abatimento na forma de dinheiro.

2 - conseqüentemente, com fundamento no inciso II do artigo 586 do Regulamento do ICMS, ficam reformadas todas as demais respostas dadas pela Consultoria Tributária e que, versando sobre a mesma matéria, concluíram de modo diverso.

3 - Esta decisão produzirá efeitos a partir da sua publicação.” 
De acordo com o artigo roo do Código Tributário Nacional, a presente decisão trata-se de "Norma Complementar", e de acordo com os ensinos do ilustre Professor Hugo de Brito Machado:

diz-se que são normas complementares porque se destinam a completar o texto das leis, dos tratados e convenções internacionais e decretos. Limitam-se a completar. Não podem inovar ou de qualquer forma modificar o texto da norma que complementam." ${ }_{4}$

\section{I. Da violação à Constituição Federal e ao Código Tributário Nacional}

A praticada concessão de bonificações em lugar de simples descontos se assenta no princípio constitucional da livre iniciativa hospedado no artigo $\mathrm{I}^{\mathrm{o}}$, inciso IV, da Constituição Federal e, ainda, no princípio da livre concorrência, posto no inciso IV do artigo I으, combinado com o artigo I70, também da Constituição Federal.

As inconstitucionalidades e ilegalidades são nítidas, pois a decisão proferida pelo Coordenador da Administração Tributária, bem como a execução de suas determinações, violam expressamente o artigos $5^{\circ}$, inciso II e 146 , inciso III, alínea “a”, e o artigo I50, inciso I, da Constituição Federal, que assim prescrevem

Artigo $5^{\circ}$ - Todos são iguais perante a lei, sem distinção de qualquer natureza, garantindo-se aos brasileiros $e$ aos estrangeiros residentes no País a inviolabilidade do direito à vida, à liberdade, à igualdade, à segurança e à propriedade, nos termos seguintes:

II - ninguém será obrigado a fazer ou deixar de fazer alguma coisa senão em virtude de lei;"

“Artigo I46 - Cabe à lei complementar:

III - estabelecer normas gerais em matéria de legislação tributária, especialmente sobre:

a) definição de tributos e de suas espécies, bem como, em relação aos impostos discriminados nesta Constituição, a dos respectivos fatos geradores, bases de cálculo e contribuintes;”

“Artigo 150 - Sem prejuízo de outras garantias asseguradas ao contribuinte, é vedado à União, aos Estados, ao Distrito Federal e aos Municípios:

I - exigir ou aumentar tributo sem lei que o estabeleça;"

Por meio de mera leitura dos dispositivos constitucionais, revela-se, de per se, a arbitrariedade dos atos realizados pelo Impetrado, que autua contribuintes que não integram na base de cálculo do ICMS os valores correspondentes às bonificações, pois os executa com base em decisão administrativa, e não com base em lei, fato este inadmissível

4 Hugo de Brito Machado. Curso de direito tributário., p. 8o 
em face do que dispõe a Constituição Federal e, especialmente, em razão do fato de que há legislação específica em vigor que rege a matéria ora discutida, qual seja, a exclusão da base de cálculo do ICMS os valores correspondentes aos descontos incondicionais, no caso em debate as denominadas bonificações.

Ressalte-se, ainda, que a decisão normativa emanada do Coordenador da Administração Tributária não possui força de lei, haja vista que não cabe a esta Autoridade Administrativa o poder de legislar e muito menos de proferir decisões a serem executadas de forma contrária ao disposto na legislação vigente, conforme inclusive, preceitua os artigos $6^{\circ}$ e $7^{\circ}$ do Código Tributário Nacional:

Artigo 6으 - A atribuição constitucional de competência tributária compreende a competência legislativa plena, ressalvadas as limitações contidas na Constituição Federal, nas Constituições dos Estados e nas Leis Orgânicas do Distrito Federal e dos Municípios, e observado o disposto nesta Lei."

“Artigo $7^{\circ}$ - A Competência tributária é indelegável, salvo atribuição das funções de arrecadar ou fiscalizar tributos, ou de executar leis, serviços, atos ou decisões administrativas em matéria tributária, conferida por uma pessoa jurídica de direito público a outra, nos termos do $\S 3^{\circ}$ do artigo I 8 da Constituição.”

Neste sentido, Paulo Lucena de Menezes, ao comentar os artigos $6^{0}$ a $8^{0}$ do Código Tributário Nacional, assim ilustra a matéria:

No caso específico do regime federativo brasileiro, a Constituição Federal restringe a esfera de atuação das pessoas políticas no plano tributário, conferindolhes os recursos necessários para o exercício de suas atribuições e a plena realização de seus fins, o que é feito basicamente de duas formas distintas, quais sejam: autorizando-lhes instituir determinados tributos e assegurando-lhes a participação na arrecadação de tributos instituídos pelos outros entes tributantes.

No que diz respeito à primeira hipótese - a segunda será objeto de análise no tópico 5 infra - , a Constituição Federal não cria tributos, mas tão somente outorga tal aptidão a entes públicos especificados, que podem ou não exercê-la, segundo os seus próprios interesses políticos e econômicos. (...)

Como nas sociedades modernas não mais se admite a imposição arbitrária de tributos, tal qual se verificava em passado remoto, o exercício da competência tributária encontra-se adstrito ao plano legislativo.

Com efeito, uma vez que o sistema tributário pátrio consagra o princípio da legalidade (CF, art. I5o, I), o exercício dessa competência não apenas se opera, como também se esgota com o advento de veículo normativo qualificado que venha a definir o perfil do tributo, o qual é atribuição constitucionalmente reservada à lei. Em outras palavras cabe privativamente à lei traçar com precisão todos os elementos essenciais da imposição tributária, demonstrando previamente a situação econômica que se procura alcançar, sem deixar margem à utilização de critérios subjetivos."

5 Paulo Lucena de Menezes. Comentários ao Código Tributário Nacional, p. 38 
Ora, se não cabe nem mesmo aos entes da federação competentes exigir tributos sobre fatos geradores não previstos em lei complementar (artigo 146 , inciso III, "a" da Constituição Federal), muito menos poderia a Administração Tributária legislar e, através de seus agentes fiscais, baseados em decisão normativa administrativa, exigir dos contribuintes valores que não integram a base de cálculo do tributo ICMS, no caso em tela, os valores correspondentes às bonificações, pois estas não são descritas como fato gerador da exação em comento e são taxativamente excluídas de sua base de cálculo por força do disposto na Lei Complementar n.. 87, de 13 de setembro de 1996 e na Lei 6.374/89, com a redação da Lei n.ำ Io.6ı/oo, como demonstrado anteriormente.

Sendo assim, havendo flagrante confronto da Decisão Normativa CAT n. ${ }^{\circ}$ 4/oo, proferida pelo Coordenador da Administração Tributária, aos ditames constitucionais e à legislação em vigor, verifica-se que não há respaldo à exigência de que o valor correspondente às bonificações concedidas pelo comerciante vendedor aos seus clientes compradores seja integrado à base de cálculo do tributo ICMS.

Salta aos olhos que a própria Consultoria Tributária da Secretaria da Fazenda manifestava-se favoravelmente à exclusão das bonificações da base de cálculo de ICMS, em posição antagônica à adotada pela Coordenadoria da Administração Tributária do Estado. Veja-se a título de exemplo, o teor da resposta à Consulta n.o $567 / 96$ :

\begin{abstract}
os descontos ou abatimentos concedidos na forma de valor representam vantagem auferida pelo destinatário e não pelo contribuinte remetente e quando concedidos independentemente de condição excluem-se da base de cálculo do imposto. A bonificação, por sua vez, constitui, em última análise, abatimento dado sob a forma de unidades físicas de produto. (...) Sendo a bonificação igualmente incondicional, da mesma forma se excluirá da base de cálculo o valor das mercadorias bonificadas. (...) Cabe-nos esclarecer, que o entendimento acima aplica-se, tão somente, quando se tratar de operação única e processada em uma mesma Nota Fiscal, ou seja, quando a mercadoria bonificada estiver diretamente vinculada a uma operação de compra e venda, de sorte que sem esta aquela não existiria."
\end{abstract}

Na mesma linha, o Tribunal de Impostos e Taxas do Estado de São Paulo, órgão integrante da própria Secretaria da Fazenda, também se posicionava neste sentido, conforme se extrai do voto de lavra do Juiz Eduardo Perez Salusse:

Note-se que as bonificações consistem na entrega de uma quantidade maior que a efetivamente comprada sem que o vendedor cobre qualquer valor adicional pela diferença, caracterizando-se, portanto, em abatimentos por meio de produtos. Assim, as bonificações são um modo de o vendedor conseguir um melhor resultado em seus negócios, caracterizando-se como descontos incondicionais (...)" (Processo n. ${ }^{\mathrm{o}}$ 23708-173497/2002) 


\subsection{Do posicionamento do Superior Tribunal de Justiça}

O Superior Tribunal de Justiça, em recentíssimas decisões, tem manifestado entendimento de que o valor dos descontos incondicionais oferecidos nas operações mercantis deve ser excluídos da base de cálculo do ICMS:

TRIBUtÁrio. RECURSO ESPECIAL. ICMS. BASE DE CÁlCUlO. DESCONTO CONDICIONADO.

I. "Os valores concernentes aos descontos ditos promocionais, assim como os descontos para pagamento à vista, ou de quaisquer outros descontos cuja efetivação não fique a depender de evento futuro e incerto, não integram a base de cálculo do ICMS, porque não fazem parte do valor da operação da qual decorre a saída da mercadoria"(Hugo de Brito, Direito Tributário - II, São Paulo, Editora RT, 1994, pág. 237).

2. O valor dos descontos incondicionais oferecidos nas operações mercantis deve ser excluídos da base de cálculo do ICMS, ao passo que os descontos concedidos de maneira condicionada não geram a redução do tributo. Precedentes.

3. Na hipótese, o desconto efetuado pela recorrente estava condicionado à utilização de financiamento oferecido por empresa do mesmo grupo, sem valia para quem efetuasse as compras utilizando-se de dinheiro, cartão de crédito ou cheque.

4. Recurso Especial Improvido." (RESP 432472/SP; Recurso Especial 2002/o050896-6, Relator Ministro Castro Meira, Órgão Julgador - Segunda Turma, Data do Julgamento 09/II/2004, Data da Publicação/Fonte DJ 14/02/2005)

TRIBUTÁRIO. IMPOSTO SOBRE PRODUTOS INDUSTRIALIZADOS. INCLUSÃO DO VALOR DO FRETE REALIZADO POR EMPRESA COLIGADA NA BASE DE CÁLCULO. VALOR REAL DA OPERAÇÃO. DESCONTOS INCONDICIONAIS. IMPOSSIBILIDADE. OFENSA AO ART. 47 DO CTN. PRECEDENTES.

I. A alteração do art. I4 da Lei n. ${ }^{\circ}$ 4.502/64 pelo art. Is da Lei n.o 7.798/89 para fazer incluir, na base de cálculo do IPI, o valor do frete realizado por empresa coligada, não pode subsistir, tendo em vista os ditames do art. 47 do CTN, o qual define como base de cálculo o valor da operação de que decorre a saída da mercadoria, devendo-se entender como valor da operação o contrato de compra e venda, no qual se estabelece o preço fixado pelas partes.

2. A jurisprudência do Superior Tribunal de Justiça envereda no sentido de que:

- “Consoante explicita o art. 47 do CTN, a base de cálculo do IPI é o valor da operação consubstanciado no preço final da operação de saída da mercadoria do estabelecimento. O Direito Tributário vale-se dos conceitos privatísticos sem contudo afastá-los, por isso que o valor da operação é o preço e, este, é o quantum final ajustado consensualmente entre comprador e vendedor, que pode ser $o$ resultado da tabela com seus descontos incondicionais. Revela contraditio in terminis ostentar a Lei Complementar que a base de cálculo do imposto é o valor da operação da qual decorre a saída da mercadoria e a um só tempo fazer integrar ao preço os descontos incondicionais. Ratio essendi dos precedentes quer quanto ao IPI, quer quanto ao ICMS.” (Resp n. ${ }^{\circ}$ 477525/GO, Rel. Min. Luiz Fux, DJ de 23.06.2003) 


\begin{abstract}
A base de cálculo do Imposto sobre Circulação de Mercadorias e Serviços ICMS, é o valor da operação, o que é definido no momento em que se concretiza a operação. $O$ desconto incondicional não integra a base de cálculo do aludido imposto." (Resp n. ${ }^{\mathrm{o}}$ 63838/BA, Rel. ${ }^{\mathrm{a}}$ Min. ${ }^{\mathrm{a}}$ Nancy Andrighi, DJ de 05.06.2000)

3. Precedentes das $\mathrm{I}^{\underline{a}}$ e $2^{\underline{a}}$ Turmas desta Corte Superior.

4. Recurso não provido.” (Processo REsp. 667950/RN; Recurso Especial 2004/oroos68-3 Relator Ministro José Delgado, Órgão Julgador - Primeira Turma, Data do Julgamento 04/II/2004, Data da Publicação/Fonte DJ $13 / 12 / 2004$ )
\end{abstract}

TRIBUTÁRIO. ICMS. DESCONTOS INCONDICIONAIS. BASE DE CÁlCULO.

A base de cálculo do Imposto sobre Circulação de Mercadorias e Serviços ICMS, é o valor da operação, o que é definido no momento em que se concretiza a operação. $O$ desconto incondicional não integra a base de cálculo do aludido imposto.” (RESP 63838/BA; Recurso Especial 1995/oor7842-7; Relatora Ministra Nancy Andrighi, Órgão Julgador - Segunda Turma, Data do Julgamento 09.05.2000, Data da Publicação/Fonte DJ 05.06.2000)

\title{
CONCLUSÃO
}

A não incidência do tributo ICMS sobre o valor das mercadorias remetidas a título de bonificação se justifica não somente pelos evidentes desrespeitos à legislação vigente, mas acima de tudo pelos princípios que permeiam este tributo.

A capacidade contributiva, constante no artigo 202 da Constituição Federal de 1946 e primeira parte do artigo $145, \S^{\circ}$ da Constituição Federal de 1988 , é elemento essencial do tributo ICMS, no entanto, na presente situação o mesmo não pode ser aplicado ou aferido face a ausência de signo presuntivo de riqueza.

Ora, a base de cálculo do ICMS deve corresponder ao valor da operação ou o preço que o contribuinte vendedor recebe, isto é, o imposto só deve alcançar aquilo que entra para o seu patrimônio.

Ocorrendo de maneira diversa, como vem ocorrendo, configura-se o confisco, expressamente vedado pelo artigo I5o, inciso IV da Constituição Federal.

\section{BIBLIOGRAFIA}

BASTOS, Celso Ribeiro. Curso de direito financeiro e de direito tributário. 6. ed. São Paulo: Saraiva, 1998.

BORGES, Humberto Bonavides. Planejamento tributário: IPI, ICMS, ISS e IR. 9.ed. São Paulo: Atlas, 2006. 
BORGES, Humberto Bonavides. Gerência de impostos: IPI, ICMS e ISS. 5.ed. São Paulo: Atlas, 2004.

CARRAZZA, Roque Antonio. ICMS. 9.ed. São Paulo: Malheiros, 2003.

CASSONE, Vittorio. Direito tributário. ıo.ed. São Paulo: Atlas, 1997.

DIFINI, Luiz Felipe Silveira. Manual de direito tributário. 2.ed. São Paulo: Saraiva, 2005.

FABRETTI, Láudio Camargo. Código tributário nacional comentado. 6.ed. São Paulo: Atlas, 2005.

MACHADO, Hugo de Brito. Curso de direito tributário. 22.ed. São Paulo: Malheiros, 2003.

MATTOS, Aroldo Gomes de. ICMS: comentários à legislação nacional. São Paulo: Dialética, 2006.

MELO, José Eduardo Soares de. ICMS: teoria e prática. 8.ed. São Paulo: Dialética, 2005.

Revista Dialética de Direito Tributário. São Paulo: Dialética, $n^{\circ} 47$, ago. 1999. ROCHA, Valdir de Oliveira (Coord.). Grandes questões atuais do direito tributário. 9.v. São Paulo: Dialética, 2005.

ROCHA, Valdir de Oliveira (Coord.). Grandes questões atuais do direito tributário. Io.v. São Paulo: Dialética, 2006. 